\title{
DECISÃO POR SUPERMAIORIA NAS CORTES \\ CONSTITUCIONAIS: O CASO DAS EMENDAS CONSTITUCIONAIS \\ INCONSTITUCIONAIS
}

\section{DECISION BY SUPERMAJORITY IN CONSTITUTIONAL COURTS: THE CASE OF UNCONSTITUTIONAL CONSTITUTIONAL AMENDMENTS}

RESUMO: As principais críticas que a perspectiva do constitucionalismo político de Jeremy Waldron e Richard Bellamy lança em direção ao controle de constitucionalidade forte são fundamentadas na ideia de autogoverno e na noção de igualdade política. Para esses autores, a regra majoritária simples representa um importante mecanismo que impõe o igual respeito às diferentes visões políticas. Apesar de aceitarem o controle de constitucionalidade fraco, os constitucionalistas políticos desconsideram a emenda constitucional como mecanismo para representar uma maneira de mitigar a supremacia judicial. Em razão disso, seus argumentos não alcançam os sistemas jurídicos de controle forte com previsão de emenda constitucional. Em razão dessa lacuna teórica, a presente pesquisa partiu do seguinte problema: em que medida é possível analisar o controle de constitucionalidade de emenda constitucional a partir dos pressupostos democráticos do constitucionalismo político? Apesar da contrariedade dos constitucionalistas políticos às supermaiorias, concluiu-se que a possível desvantagem da maioria qualificada no parlamento não tem a mesma razão de ser para uma decisão judicial. A presunção da manutenção do status quo da supermaioria no controle de constitucionalidade de emenda serve para tornar a decisão sobre o afastamento mais exigente, em razão da carga democrática que o poder de reforma constitucional detém.

Palavras-chave: Maioria simples; Controle de constitucionalidade; Constitucionalismo político; Poder de reforma.

\footnotetext{
${ }^{1}$ Doutor em Direito Constitucional (USP). Professor do Programa de Pós-Graduação em Ciência Jurídica da Universidade Estadual do Norte do Paraná (UENP). Contato: jaironlima@yahoo.com.br.
} 
ABSTRACT: The key criticisms of strong judicial review made by Jeremy Waldron and Richard Bellamy, from the perspective of political constitutionalism, are based on the ideal of self-government and political equality. The political constitutionalist theory holds that the bare majority represents an important mechanism which imposes equal respect for the different political views. Although they accept weak judicial review, political constitutionalists ignore the fact that a constitutional amendment is a mechanism which can mitigate the judicial supremacy. When these critics refuse to accept the potential of amendments to provide such mitigation, they exclude the legal systems of strong judicial review with constitutional amendments. Because of this gap in the theory, this paper is intended to address the following issue: to what extent is it possible to analyze the judicial review of constitutional amendment based on the democratic assumptions of political constitutionalism? Although political constitutionalists are opposed to supermajorities, the conclusion is that the possible disadvantage that they see in a qualified majority in parliament does not apply in the same way to a court decision. The presumption of maintenance of the status quo which a super-majority implies, when it comes to the judicial review of an amendment, serves to make a decision to reject the amendment more difficult, bearing in mind the democratic weight of the amending power.

Keywords: Bare majority; Judicial review; Political constitutionalism; Amending power.

\section{INTRODUÇÃO}

A teoria constitucional contemporânea tem dedicado grandes esforços em torno do papel que as cortes constitucionais desempenham na garantia de direitos fundamentais em sociedades democráticas. Diversos autores analisaram as implicações negativas desse fenômeno, tais como Jeremy Waldron (1999), Richard Bellamy (2007), Mark Tushnet (1999) e Larry Kramer (2004). No entanto, eles não fazem parte de um grupo homogêneo, pois provêm de tradições filosóficas distintas: liberal em Waldron, republicana em Bellamy e democrático-popular em Tushnet e Kramer. Apesar disso, é possível dizer que são representantes do constitucionalismo político, pois eles têm em comum a busca pela restauração do aspecto político do constitucionalismo.

Diversamente de uma investigação sobre a legitimidade do judicial review, este texto se direciona para uma leitura do judicial review a partir das críticas dos autores mencionados, a fim de demonstrar formas de potencializar democraticamente esse instituto. Por essa razão, toma-se como ponto de partida a presença das cortes constitucionais nos diversos sistemas constitucionais democráticos pelo mundo e se questiona: em que medida o controle jurisdicional de constitucionalidade, em 
especial de emenda constitucional, pode ser exercido a partir da inclusão das críticas feitas pelo constitucionalismo político de Jeremy Waldron e Richard Bellamy?

Para desenvolver esse argumento, serão apresentadas as principais críticas ao judicial review a partir de Waldron e Bellamy, com destaque especial à igualdade política da regra de maioria, bem como será demonstrada a lacuna teórica existente em torno da emenda constitucional para esses autores. No item seguinte, serão destacados os elementos democráticos do poder de reforma e a sua natureza distinta em relação ao poder constituinte originário e aos poderes constituídos. Por fim, será abordado o problema das emendas constitucionais inconstitucionais e a ressignificação método de decisão de maioria qualificada, aqui chamada de supermaioria.

\section{DEMOCRACIA E REGRA DE MAIORIA PARA O CONSTITUCIONALISMO POLÍTICO}

Para debater a legitimidade das cortes constitucionais Jeremy Waldron e Richard Bellamy assumem a premissa de que nós vivemos em uma sociedade complexa e plural, na qual as pessoas discordam sobre o sentido de justiça e o conteúdo dos direitos fundamentais. Essa condição de desacordos não significa que temos que abandonar a necessidade de definição de uma visão comum na sociedade. Pelo contrário, deve-se pensar a atividade política de decisão coletiva inserida no contexto de discordâncias. A partir desse ponto de partida, esses autores questionam qual seria a instituição responsável para fazer cessar esses desacordos.

O problema que incomoda Jeremy Waldron se encontra na importância secundária que se concede à legislação em comparação ao judicial review quando se está discutindo a definição dos direitos fundamentais que vão reger uma determinada comunidade. Ele acredita que uma das razões pelas quais o judicial review alcançou ampla crença em relação à sua legitimidade reside justamente nas revelações das falhas da decisão majoritária dos parlamentos, a qual pode gerar a tirania da maioria ${ }^{2}$ e, por isso, a atuação contramajoritária das cortes. Ocorre que muitas cortes constitucionais, apesar da apresentação de justificativas, também utilizam o mesmo método de decisão. Por essa razão, a diferença entre cortes e parlamentos estaria na origem eleitoral do último e não em seus métodos de decisão (WALDRON, 1999, p. 90-91). O judicial review seria, desse modo, apenas uma segunda rodada de decisão feita por membros sem legitimidade eleitoral.

Tanto Waldron como Bellamy argumentam que a regra de maioria presente nas decisões dos parlamentos acrescenta respeitabilidade moral para a tarefa de

\footnotetext{
${ }^{2}$ De acordo com Alexis de Tocqueville, a tirania da maioria se expressa por meio da máxima de que o povo tem direito de fazer tudo. Entretanto, ele rejeita essa concepção mediante a justificativa da existência do direito a desobedecer a uma lei injusta. Isso não significa dizer que Tocqueville estava contestando o direito de comando da maioria, ao invés disso, recorria à soberania da humanidade em contraposição à soberania popular (TOCQUEVILLE, 2003, p. 215).
} 
escolher o conteúdo dos direitos diante de várias opções discordantes. Isso porque ela tem a vantagem de dar o mesmo peso para as opiniões de cada um dos membros do processo decisório, tornando cada opinião decisiva para o resultado final (BELLAMY, 2007, p. 38). Ronald Dworkin (2010, p. 1085) discorda de Waldron no tocante a essa questão, pois ele acredita que a regra de maioria não é um princípio geral de justiça independentemente do contexto. Em contraposição à crítica de Dworkin, Waldron reconhece que o método majoritário também pode ser usado em ambientes não democráticos (WALDRON, 2010, p. 1044-1050).

Em razão da importância que a regra majoritária assume no processo decisório dos parlamentos, é frequente associá-la à ideia de tirania da maioria. Waldron (2006, p. 1396-1399) e Bellamy (2007, p. 37-28) não negam que a tirania da maioria seja possível, mas ela não é o resultado necessário de uma circunstância de desacordos entre os direitos decidida pela regra majoritária. Decisões que não protegem direitos fundamentais são um conceito substantivo, ou seja, tanto o parlamento como a corte podem errar. O problema encontra-se no fato de que se o parlamento erra haveria uma corte para corrigir. Mas o que acontece quando a corte também erra? Não há nenhum procedimento que garanta que as cortes irão produzir, necessariamente, decisões protetivas dos direitos fundamentais, em especial das minorias.

Além disso, há um grande número de leis que não são o resultado de uma maioria homogênea que impõe sua vontade sobre uma minoria consistente. Pelo contrário, muitas vezes as leis correspondem a uma série de compromissos intermediados por coalizões de diferentes grupos minoritários, principalmente nos sistemas proporcionais e multipartidários. Não há arbitrariedade quando um governo possui maioria legislativa para aprovar seus programas, os quais foram vencedores em uma eleição livre e justa. Para Waldron e Bellamy, a arbitrariedade estaria em considerar peso superior à visão de alguns indivíduos não-eleitos sobre outros eleitos, tal como no judicial review. Perder em um processo majoritário não é a mesma coisa que fazer parte de uma minoria que não têm o mínimo de proteção legal (BELLAMY, 2007, p. 241-255).

Nesse ponto, é indispensável indicar que a regra majoritária defendida por Waldron e Bellamy se trata daquilo que se conhece como maioria simples (bare majority), em que a decisão de $50 \%$ mais 1 dos votantes se torna vinculante para todos. Na perspectiva do constitucionalismo político, a maioria qualificada (supermaioria) não tem os mesmos méritos da maioria simples, pois ela desrespeita a ideia fundamental de tratamento equânime entre as opiniões ao conceder um favorecimento àqueles que apoiam a manutenção do status quo, exigindo dos adversários um número de votos maior do que 50\% mais 1 . Exemplificativamente: imagine um grupo de votantes de 100 membros que precisa decidir sobre uma alteração legislativa, os quais têm as seguintes opções: 1) favorável à alteração; 2) desfavorável à mudança. Método de decisão eleito: aprovação da alteração se dará apenas com a maioria de $3 / 5$ dos votantes. Nessa situação existe uma dificuldade 
muito maior de aprovação da opção 1 em comparação com a opção 2, pois basta à opção 2 atingir o número de 41 votos para que ela já se torne vencedora. Diferentemente, a vitória da opção 1 exige um número muito maior de apoio, qual seja, 60 votos (3/5). Nesse esquema decisório as opções 1 e 2 não são tratadas de forma equânime, somente a utilização da regra de maioria simples faria isso ao exigir tanto de 1 e 2 a necessidade de 51 votos para a vitória.

Apesar das críticas contundentes ao controle judicial de constitucionalidade, não se pode entender a posição de Jeremy Waldron em termos totalmente excludentes ao judicial review, pois seus textos posteriores a Law and Disagreement apresentaram uma maior delimitação da abrangência de suas críticas, inclusive com a estipulação de condições para que elas tenham aplicação. Esse movimento teórico também pode ser observado em Richard Bellamy. Nesse caso, o autor indicou as possíveis interações entre o constitucionalismo político britânico e a emergência da corte constitucional nacional pós Human Rights Act e da Corte Europeia de Direitos Humanos. Atualmente, ambos os autores reconhecem o desempenho das cortes constitucionais no âmbito do weak judicial review, no qual a interpretação judicial da constituição não é final e vinculante aos demais ramos do poder, ou seja, a supremacia judicial ${ }^{3}$.

Em linhas gerais, o constitucionalismo político coloca a discussão em torno do conteúdo dos direitos fundamentais sob a disputa de um processo político ordinário, ou seja, com a desconsideração da existência de momentos distintos no âmbito da política democrática: um constituinte e outro constituído (na perspectiva de Joseph Sieyès) ou um normal e outro constitucional (na visão de Bruce Ackerman). Para o constitucionalismo político, o processo constituinte é contínuo e acontece dentro das circunstâncias de desacordo social. Por essa razão, a constituição política é criada e emendada no dia a dia da política (GEE; WEBBER, 2010, p. 288-189).

Por essa razão, está ausente nas discussões do constitucionalismo político uma reflexão mais detida em torno de um momento constitucional fixo temporalmente. De acordo com Marco Goldoni (2012, p. 943-946), essa afirmação revela a principal fraqueza da concepção política dos constitucionalistas políticos, pois eles entendem que a política surge em um reino sem limitações, ou seja, sem nenhuma força externa (poder constituinte) para gerá-la. Todavia, as instituições políticas não

\footnotetext{
3 “A supremacia judicial, com sua associada tendência à exclusividade e ao monólogo no raciocínio dos direitos, é especialmente problemática no inevitável contexto de razoável desacordo do mundo real - entre juízes, entre cortes e Legislativo e entre cidadãos - quanto ao significado, alcance, aplicação e limites permissíveis do texto relativamente abstrato de uma declaração de direitos" (GARDBAUM, 2010, p. 173, tradução livre). "Judicial supremacy, with its associated tendency toward exclusivity and monologue in rights reasoning, is especially problematic in the inevitable real world context of reasonable disagreement-among judges, between courts and legislatures, and among citizens-regarding the meaning, scope, application, and permissible limits on the relatively abstract text of a bill of rights." (GARDBAUM, 2010, p. 173).
} 
operam no vácuo e não surgem do nada. O constitucionalismo político deixa de levar em consideração a fragilidade do reino político onde a ação é tomada. A característica mundana da ação política impõe uma concepção temporalmente estendida que proporciona um antes e um depois. Parte do objetivo da ação política significa a manutenção e a renovação do mundo comum partilhado entre os homens. Evitar esse aspecto da realidade significa, portanto, a idealização das circunstâncias da política.

Em razão da rejeição da ideia de poder constituinte por parte do constitucionalismo político, por consequência, também não há qualquer discussão em relação ao papel desenvolvido pelas emendas constitucionais. No entanto, na medida em que o constitucionalismo político reconhece o desempenho das cortes no weak judicial review, poderia haver por parte dessa linha teórica certa atenção em relação à possibilidade de emendas constitucionais exercerem alguma função nesse tipo controle. A razão para essa afirmação encontra-se no fato de que as emendas constitucionais serviriam como mecanismos de respostas legislativas ao entendimento das cortes constitucionais e, assim, mitigariam as críticas democráticas ao strong judicial review.

Rosalind Dixon e Adrienne Stone (2014, p. 9) apresentam três razões pelas quais o constitucionalismo político rejeita a emenda constitucional como mecanismo adequado a promover interação com o Legislativo, quais sejam: a inviabilidade prática em razão dos requisitos exigentes do processo de aprovação da emenda; o desrespeito à regra da maioria a partir do momento em que se exige um quórum qualificado para a aprovação da emenda e, por fim, a ideia de que a emenda constitucional é um fator que contribui para a prolixidade do texto constitucional.

Pode-se afirmar que Jeremy Waldron representa o argumento da inviabilidade prática, já que suas críticas ao controle de constitucionalidade visualizam a realidade constitucional norte-americana, na qual o processo de emenda à Constituição é bastante exigente ${ }^{4}$. Essa dificuldade prática impede que a emenda constitucional seja uma resposta legislativa frequente e contínua, pois a sua aprovação exige grandes compromissos nacionais (DIXON; STONE, 2014, p. 10). No que diz respeito a Richard Bellamy, não se pode deixar de pontuar que os seus argumentos partem do contexto político-constitucional britânico, no qual ele está inserido. Por essa razão, sua proposta de constitucionalismo político não abrangeria a dualidade entre poder constituinte originário e poder constituinte derivado, pois a constituição é o próprio processo político contínuo e ordinário. Em razão disso, não haveria justificativas para que a interpretação da constituição fosse alterada por meio de um procedimento mais dificultoso, pois sua interpretação se

${ }^{4}$ Dentre os diversos processos de emenda constitucional existentes pelo mundo, a teoria constitucional cita o caso norte-americano como exemplo de procedimento com o maior nível de dificuldade na alteração constitucional (DIXON; STONE, 2014, p. 10). Donald Lutz, ao comparar os requisitos de alteração constitucional em 32 países, concluiu que os EUA apresentam uma dificuldade mais do que o dobro da média de todos os países (LUTZ, 1994, p. 369). 
dá no dia a dia do processo político, na dependência maior de barreiras políticas do que jurídico-procedimentais. Além disso, ambos se situam no fato de que a exigência de uma supermaioria para a aprovação de emendas constitucionais representa uma violação ao postulado democrática da igualdade política, já que essa técnica decisória não trata de forma equânime as opções em disputa: aprovação ou não aprovação da emenda.

Desse modo, a partir da perspectiva interna do constitucionalismo político, a emenda constitucional não tem o condão de mitigar as fragilidades que essa perspectiva crítica vê no strong judicial review. Todavia, é importante desenvolver essa análise sobre a emenda constitucional, pois a pertinência das críticas do constitucionalismo político ultrapassa o contexto geográfico vislumbrado por Waldron e Bellamy.

\section{POR UM PODER DE REFORMA CONSTITUCIONAL DEMOCRÁTICO}

Atualmente, a ideia de poder constituinte está associada à soberania popular, em razão do seu próprio valor semântico de "instituição em conjunto". O verbo constituir tem origem latina no vocábulo constituere, o qual, por sua vez, é formado a partir do prefixo co (companhia, sociedade, concomitância) somado ao verbo instituere (estabelecer), gerando o sentido de um estabelecimento em conjunto. Diversamente da soberania entendida como supremo comando individualizado, o poder constituinte demanda um engajamento intersubjetivo e cooperativo, o qual se dá por meio de procedimentos democráticos. Por essa razão, a legitimidade de uma constituição depende da condição de atendimento, pelo ato criador, dos princípios de participação e inclusão, ou seja, às prescrições normativas do seu sentido semântico (KALYVAS, 2005, p. 235-239). No processo de emergência do poder constituinte interessa muito mais a investigação em torno do compartilhamento de valores democráticos do que a verificação de suas propriedades formais.

Tanto a liberdade de decisão como a participação popular são elementos essenciais para uma concepção democrática do poder constituinte apta a contribuir para a legitimidade constitucional. Frise-se, no entanto, que essa liberdade não alcança a exclusão dos fundamentos do exercício dessa própria faculdade. "Tal como a democracia, o poder constituinte se destrói quando viola as condições que o fizeram possível" (COLÓN-RÍOS, 2012, p. 118, tradução livre) 5 . Além disso, essa associação democrática amplia a extensão da participação popular para atingir o nível de alteração constitucional, já que geralmente esse engajamento se encontra confinado nos limites da política ordinária.

As constituições que são criadas a partir de um amplo debate público e participativo são mais hábeis para promover o conhecimento comum sobre o conteúdo do texto, consequentemente, tendem a gerar maior cumprimento do

\footnotetext{
5 "Like democracy, constituent power destroys itself when it violates the conditions that make it possible." (COLÓN-RÍOS, 2014, p. 118).
} 
pacto pelos indivíduos e demais atores políticos. “O processo constituinte que é altamente aberto e inclusivo (ou ao menos que aparenta ser) aumenta a consciência e respeito dos cidadãos pelo documento assim como a confiança de que outros cidadãos desenvolveram a mesma consciência e respeito" (ELKINS; GINSBURG; MELTON, 2009, p. 97, tradução livre) ${ }^{6}$.

Para Joel Colón-Ríos (2012, p. 139), caráter democrático do poder constituinte não se exaure na finalidade de legitimar o novo texto constitucional, mas também está presente nas formas pelas quais as constituições são reformadas, pois o poder de reforma decorre desse poder constituinte originário. No entanto, o poder de reforma não se identifica na mesma categoria do poder constituinte originário nem dos poderes constituídos. Ele não é originalmente constituinte porque sofre limitações em sua forma de expressão (procedimentos) e no alcance de suas mudanças (conteúdos materiais), isto é, perde a incondicionalidade jurídica tradicionalmente associada ao poder constituinte originário. Além disso, é insuficiente qualificar o poder de reforma como constituído quando se leva em conta o fato de que as emendas constitucionais são um ato de criação de uma nova norma constitucional que amplia ou restringe a abrangência da Constituição (ex: criação de um novo direito fundamental). Ademais, quando se compara com a legislação infraconstitucional, o poder de reforma envolve um procedimento não só de maior potencial deliberativo, como também pode indicar a participação de agentes diversos do Legislativo ordinário quando exige a ratificação da emenda por referendo, por exemplo (ROZNAI, 2017, p. 112).

Nesse sentido, são exemplos de participação popular na aprovação de emendas constitucionais as constituições: EUA (quando a ratificação se der por meio de Convenção Constitucional nos Estados-membros), França (art. 89), Áustria (art. 44 - nas situações de revisão total), Espanha (art. 166), Itália (art. 138 - na hipótese de haver requerimento específico), Dinamarca (seção 88), Irlanda (art. 46), Japão (art. 96), Chile (art. 128 - quando houver desacordo entre o Presidente da República e o Congresso Nacional sobre os termos da reforma), Colômbia (art. 377), entre outras.

Diante disso, o poder de reforma da constituição deve ser analisado a partir de sua proximidade com o poder constituinte originário, entretanto, sem se confundir com ele. O poder de reforma se consubstancia em uma divisão do próprio poder constituinte, o qual seria identificado como originário quando cria uma constituição e derivado quando apenas altera o texto constitucional. A principal característica que diferencia esses dois poderes está na relação de subordinação do poder constituinte derivado em relação ao poder constituinte originário, a qual se expressa por meio dos limites impostos ao poder de reforma. $\mathrm{O}$ poder de reforma corresponde, portanto, a uma delegação de competência concedida pelo sujeito

6 "Constitution-making processes that are highly opened and inclusionary (or at least appear to be so) increase citizens' awareness and regard for the document as well as their confidence that other citizens have developed the same awareness and respect." (ELKINS; GINSBURG; MELTON, 2009, p. 97). 
constituinte. "O poder de emenda é um poder delegado exercido por agentes constitucionais especiais. Quando o poder de emenda reforma a constituição age por procuração do povo, como seus agentes" (ROZNAI, 2017, p. 118, tradução livre $)^{7}$. Em outras palavras, o poder de reforma é outorgado pelo constituinte originário e, por isso, heterônomo. Assim, o delegante pode limitar a abrangência das competências do poder constituinte derivado (cláusulas não-emendáveis, por exemplo). Nota-se, portanto, uma relação hierárquica presente entre o poder constituinte originário e o poder de reforma, já que o primeiro é a fonte de legitimidade do segundo.

Verifica-se então que o poder de reforma se destaca do poder constituinte originário a partir da relação delegante-delegatário, pois exercita competências constitucionais nos limites impostos pela fundação constitucional. Trata-se, portanto, de faculdade situada em um ponto intermediário entre a criação inicial e a execução ordinária, ou seja, entre o poder constituinte originário e os poderes constituídos. Inclui-se, assim, na categoria de poder constituinte (em seu viés derivado), pois tem a possibilidade de alterar o próprio instrumento de delegação de poderes, desde que respeitados os limites procedimentais e materiais. Apesar da existência de uma dinâmica hierárquica entre poder constituinte originário e derivado, do ponto de vista externo não há quebra da unidade da constituição, pois os poderes constituídos encontram-se subordinados igualmente às normas constitucionais, independentemente se provenientes do texto original ou de reforma.

Essa compreensão em torno da identificação da especificidade do poder de reforma é indispensável para indicar sua proximidade com a manifestação da soberania popular a partir de seu viés constituinte. Veja-se que o reconhecimento, tanto da criação, como da modificação da constituição como um direito pertencente ao povo, já era defendido por Hamilton no ensaio Federalista no 78 (1984, p. 580). Dessa maneira, tal aproximação também informa como a emenda constitucional deve ser interpretada no âmbito do seu controle de constitucionalidade, questão objeto de análise do próximo capítulo.

\section{EMENDAS CONSTITUCIONAIS INCONSTITUCIONAIS}

Não obstante o poder de reforma ter se manifestado, a mudança constitucional poder vir a ser reavaliada por alguma instituição judicial naqueles ordenamentos que adotam alguma forma de controle de constitucionalidade de emenda constitucional, como Alemanha, Índia, Colômbia e Brasil. Sob a perspectiva do constitucionalismo político, tal faculdade suprime qualquer justificativa para a defesa da emenda constitucional como instrumento de atenuação das críticas ao judicial review, pois a reforma também estaria sujeita a um exame pelas cortes

\footnotetext{
7 "The amendment power is a delegated power exercised by special constitutional agents. When the amendment power amends the constitution, it thus acts per procurationem of 'the people', as their agents." (ROZNAI, 2017, p. 118).
} 
constitucionais, recaindo, assim, nas mesmas críticas do controle de constitucionalidade em geral.

Para que uma emenda constitucional possa ser reconhecida como inconstitucional, é preciso que haja violação a alguma restrição normativamente superior ao ato de reforma. É somente a partir da previsão de limites ao poder de reforma que se pode indagar sobre os mecanismos adequados para sancionar eventual violação. Os limites procedimentais à reforma se justificam na medida em que servem para diferenciar a produção da norma constitucional da legislação infraconstitucional (por exemplo, restrições aos legitimados à propositura de projetos de emenda, quórum superior à maioria simples para aprovação, exigência de mais de uma rodada de deliberação, manifestação dos entes federativos, participação popular por meio de referendo, intervalo temporal entre as votações). Além deles, algumas constituições também exigem a obediência a certos limites materiais (por exemplo, democracia, Turquia, art. 4; república, Itália, art. 139; secularismo, Portugal, art. 288, b; direitos fundamentais, Brasil, art. 60, § 4º , IV; dignidade humana, Angola, art. 236, a; integridade territorial, Cabo Verde, art. 285; idioma oficial, Barein, art. 120, c; e bandeira nacional, Timor Leste, art. 156, i.

De uma maneira geral, os ordenamentos constitucionais que buscam reprovar o descumprimento dos limites para o exercício do poder de reforma recorrem ao sistema de justiça, especialmente às cortes constitucionais, para reparar os desvios inconstitucionais. Todavia, quando as cortes constitucionais se assumem competentes para o exercício do controle jurisdicional de constitucionalidade de emenda constitucional ressurge todo o debate em torno das deficiências democráticas de tal arranjo institucional, já apresentado no primeiro item. No entanto, agora, com as dificuldades democráticas ainda mais potencializadas por se tratar de uma revisão sobre uma norma de hierarquia constitucional e não mais norma infraconstitucional, tal como discutido pelos autores do constitucionalismo político.

Essa distinção impõe uma compreensão específica a respeito do controle de constitucionalidade de emenda constitucional, já que o objeto de avaliação judicial carrega consigo um potencial democrático superior em relação à legislação infraconstitucional. Por essa razão, às críticas inerentes ao judicial review soma-se um tratamento próprio que a concepção democrática de emenda constitucional reivindica. Diante desse cenário, a tensão democrática presente no judicial review em geral é potencializada quando se tem a emenda constitucionalidade como objeto de avaliação judicial. De acordo com David Landau, a doutrina das emendas constitucionais inconstitucionais parece ser $\mathrm{o}$ ato mais extremo do contramajoritarianismo (LANDAU, 2013, p. 232).

Diante dessa medida contramajoritária extrema, o exercício do judicial review de emenda constitucional demanda um compromisso mais exigente com os princípios democráticos do poder de reforma. Diante da ampla presença das cortes constitucionais nas democracias contemporâneas, adota-se a perspectiva que visa 
constranger ou dificultar o controle de emendas sem postular sua eliminação completa. Dentre os caminhos possíveis para se realizar a redefinição da extensão e abrangência do judicial review em favor da potencialização democrática, podem ser incluídas as restrições de ordem interna e externa. No primeiro caso, são elencados os diversos métodos de interpretação constitucional que moderam a interferência judicial na construção do conteúdo normativo dos direitos. ${ }^{8}$ Os constrangimentos externos, de outro modo, são aqueles impostos por outros atores sobre as cortes constitucionais. Não dependem, portanto, de uma autodeferência aos trabalhos parlamentares (LIPKIN, 2006, p. 1110-1112). A presente investigação se direciona para a construção de um constrangimento externo representado pela exigência de supermaioria nas cortes para declarar a inconstitucionalidade de uma emenda constitucional, tal como será discutido em seguida.

\subsection{A regra de maioria como método de decisão}

A regra de maioria, como método para a resolução de questões em que os membros de uma coletividade discordam, é considerada o mais importante instrumento para se tomar decisões eleitorais e legislativas. Tal importância se dá em razão de sua identificação como última fonte de legitimidade democrática (OFFE, 1983, p. 719). Encontra-se, portanto, nessa afirmação, o reconhecimento da regra de maioria como o método por excelência da democracia (HEINBERG, 1932, p. 452).

Entretanto, essa regra não implica, necessariamente, democracia entendida como soberania popular, uma vez que ela pode ser utilizada em contextos diversos de instituições democráticas ou eleitorais. Além disso, da democracia não decorre, peremptoriamente, a regra de maioria, uma vez que em suas origens gregas o método democrático utilizado era representado pelo sorteio (NOVAK, 2014, p. 682).

De acordo com John Heinberg, a regra de maioria pode ser vista a partir de 3 momentos diversos (1932, p. 453-465). No primeiro deles, o método majoritário se baseia na ideia da força do maior número de vontades sobre a força minoritária, tal como o movimento de um corpo para a física. Em uma segunda vertente, o fundamento da maioria encontra subsídios na teorização do direito natural pelos contratualistas, principalmente em John Locke, os quais desenvolveram a ideia de governo como consentimento dos governados em conjunção com a igualdade política contida na expressão "um homem, um voto". Por fim, o terceiro aspecto da regra da maioria inclui a preocupação com os abusos desses métodos em face das minorias e a incursão sobre os mecanismos que um governo constitucional deve utilizar para revisar as decisões tomadas exclusivamente por critérios majoritários, como o caso do judicial review.

${ }^{8}$ Como é o caso da presunção de constitucionalidade apresentada por Edwart Dawson (2013, p. 107113). 
Tais perspectivas se restringem à ideia de maioria em sua versão simples, isto é, ao conceito de $50 \%+1$. A presença disseminada dessa regra nas diversas esferas de decisão política contemporâneas decorre do fato de que ela significa o único mecanismo de votação que é: a) decisivo: já que para um par de alternativas, gera um resultado único; b) igualitário/anônimo: se o voto de duas pessoas for trocado, o resultado final não é alterado; c) neutro: não favorece qualquer uma das alternativas; d) positivamente responsivo: os votos não podem ser contados de forma contrária (MAY, 1952, p. 680-682).

No entanto, a regra de maioria simples envolve certo grau de instabilidade institucional, já que a abertura às alterações depende apenas da mudança na composição das maiorias. Essa característica, na perspectiva do constitucionalismo político, representa propriamente uma vantagem, pois a nota democrática desse método de decisão reside na possibilidade de as questões políticas serem resolvidas ordinariamente, mediante o tratamento igualitário de todos os membros do órgão de decisão. Ademais, a maioria simples não tem incentivos para consultar a minoria ou levar em conta seus interesses, já que não depende dela para implementar suas opções políticas (SWWARTZBERG, 2014, p. 4). Por consequência, haveria uma ameaça maior de violação aos direitos da minoria e, com isso, seriam indispensáveis mecanismos que oferecessem alguma forma de proteção contra tais ações majoritárias.

De outro lado, decisões tomadas por maiorias qualificadas teriam menor potencialidade lesiva em relação aos direitos da minoria, já que dependem de uma coalização numericamente superior de vontades, isto é, os interesses de um número maior de envolvidos são importantes para o alcance do quórum de aprovação. Desse modo, instituições e procedimentos de tutela da minoria tornam-se menos indispensáveis quando se está diante de decisões fruto da regra de supermaioria, como as emendas constitucionais

Ocorre que a regra de supermaioria, ou maioria qualificada (exigência de uma percentagem maior do que $50 \%+1$ ) não satisfaz a condição de neutralidade que se encontra presente na regra de maioria simples. Isso porque, ao se exigir quórum qualificado para a aprovação de determinada decisão, a opinião daqueles que querem a aprovação da mudança depende de um número maior de apoiadores do que a simples metade mais 1. Já para os desejosos da manutenção da situação e contrários à alteração, uma minoria bem inferior (a depender da proporção elegida) tem o poder de bloquear a aprovação. Nesse tipo de arranjo não há o mesmo tratamento diante das opções "aprovação" e "não aprovação", pois se depende de um maior número de apoiadores para a primeira alternativa em relação ao que se exige para a segunda. Privilegia-se, portanto, a manutenção do status quo.

Historicamente, o documento mais antigo já encontrado a prever uma regra de supermaioria se refere à lex acilia repetundarum, da Roma Antiga, datada aproximadamente entre 123 e 122 a.C. Outros exemplos remotos de utilização da regra de supermaioria são encontrados no $3^{\text {o }}$ Concílio de Latrão (1179), o qual 
exigiu a maioria de 2/3 para a escolha do Papa, e na República Florentina, com o uso desse instrumento para a aprovação de candidatos ao cargo de magistrados (SCHWARTZBERG, 2014, p. 45-46 e 50-62).

Em sua investigação, Melissa Schwartzberg (2014, p. 20-58) identificou que a consolidação da regra de supermaioria a partir da Idade Moderna está associada ao fato de representar um método de decisão alternativo à unanimidade, pois as decisões clericais embasadas na unidade de espírito dos membros do grupo não davam conta dos desacordos que ocorriam na definição dos responsáveis para emanar esse consenso. Além disso, diante da reivindicação do mesmo status entre os cardiais, o método agregativo majoritário se tornou a opção que evitava a discussão sobre os méritos individuais de cada votante. Todavia, esse elemento de tratamento equânime não foi suficiente para explicar a adopção de regra de supermaioria, pois ainda havia o comprometimento com a ideia de unanimidade, indispensável para a legitimidade dos resultados. Em razão disso, a regra de supermaioria foi adotada para acomodar em um patamar intermediário as exigências de tratamento igualitário com a ainda presente influência do consenso unânime.

Nesse mesmo sentido, James Buchanan e Gordon Tullock (1962) assumiram a defesa da regra de supermaioria por meio do argumento de que ela simboliza a segunda melhor opção para se limitar a tirania da maioria. Para esses autores, a melhor proteção da distribuição dos direitos ocorre mediante a unanimidade, pois é a única forma que garante um resultado economicamente eficiente, uma vez que não é possível melhorar a condição de alguém sem piorar a de outro. ${ }^{9} \mathrm{O}$ único processo de agregação de preferências capaz de gerar zero de externalidade é a regra do consenso. No entanto, os altos custos de um processo decisório unânime geram a impossibilidade de sua execução. Por essa razão, a regra de supermaioria representaria a segunda melhor opção para se proteger minorias, depois da unanimidade. De acordo com esse raciocínio: uma maioria simples de $51 \%$ poderia realizar o confisco dos outros $49 \%$ dos membros do grupo, enquanto em uma supermaioria de $75 \%$, por exemplo, a ação tirânica ocorreria apenas sobre $25 \%$ dos indivíduos (BRADBURY; JOHNSON, 2006, p. 439). Note-se que esse argumento aritmético se reduz a diminuir os efeitos de uma ação tirânica, sem neutralizá-la por completo, a qual ocorreria apenas pela unanimidade.

Independentemente dos méritos e dificuldades de cada uma das regras de maioria, importa ressaltar que a tradição teórica que desenvolveu o tema está associada com os procedimentos decisórios eleitorais e parlamentares, principalmente. Todavia, quando se verifica que as cortes constitucionais também fazem uso do mesmo método majoritário (principalmente na versão de maioria simples), se constata uma lacuna explicativa em torno da utilização dessa regra nos órgãos judiciais. De acordo com Jeremy Waldron (2014, p. 1695), toma-se, portanto,

\footnotetext{
${ }^{9}$ No tocante às críticas em direção a Buchanan e Tullock, ver: John Bradbury e Joseph Johnson (2006, p. 438).
} 
a utilização da regra majoritária como algo dado, sem se atentar para a especificidade de que se trata de uma instituição sem a mesma credencial eleitoral dos órgãos parlamentes. ${ }^{10}$

\subsection{Supermaioria nas Cortes Constitucionais: sua ressignificação democrática}

Diante da lacuna na explicação do uso de métodos majoritários em cortes judiciais, Akhil Amar (2012, p. 357-360) aponta 4 fatores essenciais que ajudam a explicar a adoção da regra de maioria simples pelas cortes norte-americanas. Primeiro, a maioria simples tem propriedades matemáticas únicas que a torna a resposta óbvia diante de duas alternativas. Em segundo lugar, a partir da inspiração de John Locke sobre os fundadores da nação norte-americana, a maioria simples é considerada o princípio básico de toda assembleia. Terceiro, a Constituição dos EUA incorpora a premissa majoritária, ainda que implicitamente, pois ela especifica textualmente quando o método de decisão não se dará por maioria simples. ${ }^{11}$ Assim, se a exceção é a maioria qualificada, a regra seria a maioria simples. Por fim, a maioria simples estava presente na promulgação da Constituição dos EUA, pois ainda que não prevista, as ratificações ocorreram por meio desse método, indicando, portanto, uma certa auto evidência dessa regra de decisão.

No entanto, a alegada auto evidência da maioria simples da Suprema Corte dos EUA se tornou objeto de questionamento já em 1823, quando se propôs a primeira emenda constitucional que objetivava aumentar o quórum de decisão da Suprema Corte para exigir a unanimidade. De acordo com Evan Caminker (2003, p. 88), a mais recente proposição no mesmo sentido se deu em 1981 com a proposta que exigia a concorrência de 7 votos favoráveis para declarar uma lei inconstitucional. Frise-se, ainda, que na esfera estadual, Ohio adotou, em 1912, uma emenda constitucional estipulando o quórum de supermaioria para a declaração de inconstitucionalidade (a qual não foi mantida a partir de uma reforma em 1968), assim como Dakota do Norte e Nebraska. ${ }^{12}$

Nos EUA, portanto, as decisões da Suprema Corte tomadas por uma diferença de $5 \times 4^{13}$ incomodam aqueles que veem nessa situação a violação à doutrina da dúvida razoável, a qual estatui que os atos legislativos devem ser presumidos como constitucionais pelas cortes até que sua inconstitucionalidade seja demonstrada além de qualquer dúvida razoável, tal como ocorre na presunção de inocência.

\footnotetext{
${ }^{10}$ Mark Tushnet (2009, p. 16) acredita que as decisões tomadas por maioria simples são constitutivas da própria natureza das cortes nos EUA, tal como o mandato vitalício no âmbito do sistema judicial federal.

${ }^{11}$ Exemplos de supermaiorias na Constituição dos EUA: art. I, § 3º cl. 6; art. I, § 5, cl. 2; art. I, § 7, cl. 2; art. II, § 2, cl. 2; art. V; XIV emenda, § 3ㅜㅈXV emenda, § $4^{\circ}$.

${ }^{12}$ Sobre o contexto histórico dessas emendas, ver: Sandra Zellmer e Kathleen Miller (2015).

${ }^{13}$ Robert Riggs (1993) apresenta uma análise das decisões da Suprema Corte dos EUA por um placar de $5 \times 4$.
} 
Robert Cushman faz a ressalva, ainda, de não existir conexão necessária entre a doutrina da dúvida razoável e a regra da unanimidade, uma vez que, tal como a presunção de inocência, o formato de decisão dos juris não ocorre somente por unanimidade (CUSHMAN, 1921, p. 772, 781 e 791).

Por outro lado, existem outras cortes constitucionais que utilizam o método supermajoritário em situações bastante específicas, como é o caso do Tribunal Constitucional do Chile que, em regra, toma suas decisões por meio de maioria simples (art. 92, da Constituição chilena), mas, exige a manifestação favorável de 8 dos 10 membros do Tribunal Constitucional na declaração abstrata de inconstitucionalidade de um dispositivo já previamente declarado inconstitucional para um caso concreto (art. 93, § 7º da Constituição do Chile).

No Peru, o Tribunal Constitucional é composto por 7 juízes e adota a maioria simples, salvo para resolver a inadmissibilidade de uma demanda de inconstitucionalidade ou para declarar a inconstitucionalidade de uma norma com hierarquia de lei, quando se impõe a concordância de 5 juízes. Caso não seja atingida a maioria qualificada, o Tribunal declara infundada a demanda de inconstitucionalidade, de acordo com o art. 10 do seu regulamento normativo.

A Corte Constitucional da República Tcheca se compõe de 15 juízes e, nos casos de controle de constitucionalidade de leis em face da Constituição, bem como de controle de constitucionalidade de tratados internacionais, exige a manifestação positiva de 9 juízes ( $§ 13$, da Lei da Corte Constitucional).

No Brasil, a declaração de inconstitucionalidade de lei depende da maioria simples dos 11 juízes. No entanto, há três exceções instaurando a supermaioria de 2/3 para questões ligadas à negativa de admissibilidade de repercussão geral de recurso extraordinário; aprovação de súmula vinculante e modulação dos efeitos temporais da declaração de inconstitucionalidade.

De acordo com o art. 190 da Lei Orgânica de garantias judiciais e controle de constitucionalidade do Equador, o quórum de deliberação do pleno da Corte Constitucional será de maioria simples do total de 9 magistrados. A exceção a essa regra ocorre nos casos de destituição dos juízes da Corte, mediante 2/3 dos membros. Nesse mesmo sentido, o Tribunal Constitucional Federal da Alemanha aplica a regra de supermaioria de $2 / 3$ para o procedimento de aposentadoria antecipada ou destituição do cargo de um juiz do tribunal, de acordo com o $\S 105$ da Lei do Tribunal Constitucional Federal.

Por fim, a Turquia figura como exemplo de exigência de supermaioria exclusivamente em relação ao controle de constitucionalidade de emenda constitucional, ao impor a concorrência de $2 / 3$ dos membros da sua Corte Constitucional (art. 149 da Constituição da Turquia).

Ressalte-se, nesse ponto, que a adoção da regra de maioria, seja ela simples ou qualificada, pode estar presente tanto em cortes que se estruturam de forma seriatim como per curiam. No primeiro caso, a decisão é composta da decisão de cada membro do tribunal e, no segundo, o tribunal emite uma única decisão 
(KORNHAUSER, 2016, p. 156). A razão para essa relação independente reside no fato de que as regras em torno de unanimidade, maioria qualificada ou maioria simples são instrumentos do processo decisório do colegiado. Já a estrutura seriatim ou per curiam é um elemento pós-decisório relacionado com a maneira pela qual será publicamente exposta a divisão interna de decisão anteriormente tomada. Por essa razão, é possível que uma corte decida com base na regra de maioria dos seus membros em uma sessão fechada e, em seguida, se manifeste publicamente por meio de uma opinião per curiam, a fim de não expressar a divisão interna dos juízes e fortalecer o caráter colegial da decisão (MENDES, 2013, p. 168). Frise-se, por fim, que a discussão em torno da regra de maioria só faz sentido em cortes constitucionais que adotam formas agregativas de opiniões individuais.

Tomando-se, portanto, como ponto de partida as críticas do controle de constitucionalidade perpetradas pelo constitucionalismo político, torna-se crível afirmar que o emprego da regra de supermaioria para que as cortes constitucionais declarem a inconstitucionalidade de emendas constitucionais possui a vantagem de criar um instrumento decisório formal que dificulta o afastamento da emenda, uma vez que faz tal decisão depender da concorrência de um número maior de membros do colegiado. Em razão disso, a regra de supermaioria se constitui como um mecanismo de deferência ao poder de reforma democrático.

No âmbito do controle de emenda constitucional, essa restrição da atividade judicial se justifica pelo fato de o objeto da revisão ser uma norma fruto do poder constituinte derivado, ou seja, daquele poder que se diferencia dos poderes constituídos, uma vez que também traz consigo a possibilidade de ampliação da tutela constitucional. Essa característica impõe a esse poder de reforma exigências democráticas superiores que não estão presentes na atuação dos poderes constituídos. No âmbito, então, do strong judicial review, a atenuação das críticas democráticas a esse modo de atuar pode se concretizar mediante a adoção da regra de supermaioria para a decisão em torno do controle de constitucionalidade de emendas constitucionais.

A estipulação da regra de supermaioria no âmbito do controle de constitucionalidade de emenda também colabora com a estabilidade das decisões judiciais em comparação com a regra de maioria simples (SHUGERMAN, 2003, p. 949), uma vez que tanto a criação como a superação de um precedente vão depender de um compromisso mais exigente do ponto de vista de apoio à aprovação. Na esfera judicial, esse elemento de manutenção do status quo vai ao encontro das exigências de estabilidade das decisões, principalmente quando se está diante de cortes constitucionais, responsáveis pela uniformização da interpretação constitucional.

A partir do instante em que a regra de supermaioria torna mais custosa a aprovação de uma decisão, ela favorece a preservação da situação posta, pois um grupo minoritário inferior a 50\% menos 1 tem o poder de veto sobre a proposta em discussão. A aplicação dessa regra em uma proposta de emenda constitucional, por 
exemplo, significa a presunção da manutenção do atual texto constitucional, o qual, para ser alterado, exige um pacto mais custoso do que a mera aprovação de $50 \%$ mais 1 dos membros do grupo. Por outro lado, quando se transfere a regra supermajoritária para o controle de constitucionalidade de emenda não há como se desvincular dessa presunção de conservação do ato questionado, no caso, a emenda. Entretanto, essa presunção de manutenção do status quo da regra de supermaioria conta em favor da deferência judicial ao ato legislativo e vai ao encontro da demanda por democratização do controle de constitucionalidade.

Diferentemente das deliberações parlamentares, a presunção, ao promover pesos diferentes para as posições "constitucionalidade" vs. "inconstitucionalidade" já no início da decisão judicial, não viola a ideia de tratamento equânime entre os agentes decisores. Isso porque a igualdade política que os autores do constitucionalismo político veem violada pela regra de supermaioria diz respeito à falta de consideração equânime entre as opiniões de representantes políticos, ou seja, de indivíduos atuando em nome da coletividade. Nesse ponto, faz sentido a alegação de violação de tratamento igual, pois a igualdade política entre os legisladores é corolário da aderência à igualdade política entre os cidadãos (WALDRON, p. 1722).

Todavia, as cortes constitucionais atuam fundadas em razões que não decorrem do fato de que sejam instituições politicamente representativas. Veja-se que as críticas lançadas às cortes se dão justamente pela ausência dessa conexão democrática direta que existe nos parlamentos. Jeremy Waldron ressalta que o uso de regra majoritária em contextos eleitorais e parlamentares se justifica na agregação da maioria dos interesses, já na esfera judicial, somar votos significa contar interpretações justificáveis à luz de uma argumentação jurídica. Por isso, deve-se ter cautela quando se transfere as razões que circundam a regra majoritária no contexto parlamentar para o âmbito judicial (WALDRON, 2014, p. 1708-1709). Se nos processos de decisão parlamentar a regra de supermaioria viola a igualdade política para os constitucionalistas políticas, quando se transpõe essa regra às cortes constitucionais, o tratamento desigual das posições serve, nesse caso, para reforçar justamente o caráter democrático das emendas constitucionais ao torna-las mais difíceis de serem declaradas inconstitucionais. Ademais, juízes de cortes constitucionais não são representantes políticos que carregam pautas que merecem a mesma consideração na deliberação interna. Veja-se, nesse ponto, que Ronald Dworkin demonstra a possibilidade de utilização de arranjos institucionais nas cortes constitucionais que concedam maior peso ao voto dos juízes mais antigos, por terem mais experiência, ou ainda, maior peso ao voto dos juízes mais novo, já que eles estariam mais próximos à opinião popular em razão da recente nomeação (DWORKIN, 2010, p. 1087). Desse modo, o respeito à igualdade política, fundamento da atuação representativa nos parlamentos, não serve para justificar a impossibilidade de adoção de maiorias qualificadas como método de decisão nas cortes constitucionais. 
Importa assinalar ainda que a linha argumentativa desenvolvida nessa pesquisa não enseja necessariamente a adoção da regra de supermaioria no judicial review da legislação infraconstitucional. Isso porque a premissa assumida para a regra de supermaioria apenas em relação ao controle de emenda se baseia na natureza diversa da emenda constitucional em relação à legislação infraconstitucional. Ambos não são frutos da mesma fonte de poder, atuam sobre normas hierarquicamente distintas e suas exigências de engajamento democrático são diversas, por essa razão, necessitam de um controle de constitucionalidade não idêntico, isto é, uma forma de revisão judicial que de alguma maneira considere essas diferenças constitutivas. ${ }^{14}$

Um controle de constitucionalidade em que o nível de interferência judicial sobre a emenda e a lei infraconstitucional seja o mesmo representaria a negação de todos os pressupostos diferenciadores entre essas normas. Em razão disso, a tese da regra de supermaioria no controle de constitucionalidade de emenda não abarca a extensão do argumento ao controle de legislação infraconstitucional se isso acarretar a adoção do mesmo quórum supermajoritário para ambas as normas.

\section{CONSIDERAÇÕES FINAIS}

A partir dos argumentos expostos, evidencia-se que a conveniência da adoção da regra de supermaioria depende, necessariamente, do contexto institucional em que ela será inserida, pois, como demonstrado, ela não tem como se desvincular da sua natureza preservacionista. Esse elemento, entretanto, não é descartável em todas as arenas políticas em que há agregação de votos, sob a justificativa de tratamento desigual entre as opções elegíveis.

Primeiro, porque o tratamento igualitário que o processo democrático exige está relacionado diretamente com a representação dos cidadãos, os quais têm o direito de ver suas opiniões sendo tratadas com a mesma oportunidade e peso por parte dos representantes parlamentares. No entanto, quando se transporta a regra de maioria para a esfera judicial não se carrega conjuntamente o elemento representativo e seus corolários.

Segundo, ainda que a democracia envolva a ideia de abertura das decisões a modificações constantes em razão do desacordo social, não se pode deixar de considerar que, dentre as diversas arenas decisórias, algumas delas demandam certo grau de estabilidade maior que outras. A jurisdição constitucional, por exemplo, é construída, tanto pela natureza dos seus membros, como pelo seu arranjo institucional, com a pretensão de assegurar a constância das decisões judiciais que realizam interpretação constitucional. Nesse sentido, onde houver fortes razões para a presunção de manutenção da decisão, seja parlamentar ou judicial, a regra de supermaioria serve para satisfazer essa exigência.

\footnotetext{
${ }^{14}$ See: Carlos Bernal, Unconstitutional constitutional amendments in the case study of Colombia: an analysis of the justification and meaning of the constitutional replacement doctrine. International Journal of Constitutional Law, v. 11, nํㅡ 2, 2013.
} 
Por fim, ainda que a legitimidade do controle de emenda possa não ser aceita pelo constitucionalismo político, ao menos, pode-se afirmar que o método supermajoritário nas cortes constitucionais atende as reivindicações gerais de deferência legislativa dessas críticas. Nesse sentido, Jeremy Waldron já havia se manifestado sobre a possibilidade de instituição de supermaioria para o controle de constitucionalidade (WALDRON, 2014, p. 1730). Ademais, em discurso proferido recentemente, Waldron se manifesta no sentido de que a possibilidade de regra de supermaioria nas cortes merece ser considerada, ainda que seja um experimento, pois “Nós podemos ver um requisito supermajoritário como uma expressão institucional benéfica da presunção em favor da legislação e como um instrumento para garantir que a declaração de inconstitucionalidade aconteça apenas onde a inconstitucionalidade é induvidosa" (WALDRON, 2017, p. 13-14, tradução livre) $)^{15}$.

Nesse sentido, a regra da decisão majoritária representou o elemento utilizado para realizar essa ligação entre o argumento do constitucionalismo político em favor dos parlamentos e a justificativa da atuação das cortes constitucionais no controle de constitucionalidade. Portanto, se, à primeira vista, a regra decisória tão cara aos constitucionalistas políticos contava em desfavor do controle de constitucionalidade, a partir da investigação empreendida neste trabalho, foi possível demonstrar que o manejo da regra majoritária é flexível a diversos contextos, a depender da lógica interna que rege a coletividade em que ela será aplicada. No caso do controle de constitucionalidade, faz sentido haver esforço maior para retirar do ordenamento jurídico uma emenda constitucional, sem que isso implique em um atentado à igualdade política.

As críticas do constitucionalismo político, portanto, serviram para dar os subsídios para a construção de uma via argumentativa que "remedeie" as dificuldades democráticas enfrentadas pela ideia de controle judicial de constitucionalidade, em especial, de emendas constitucionais. A prescrição completa dos constitucionalistas políticos deixa de fora uma parte significa da tradição da teoria constitucional em torno da emenda, em razão disso, nessa pesquisa, optou-se por manter essa tradição viva, desde que tratada com doses que acolham as críticas do constitucionalismo político.

\section{REFERÊNCIAS}

AMAR, Akhil Reed. America's unwritten Constitution: the precedents and principles we live by. New York: Basic Books, 2012.

15 "We might see a supermajoritarian requirement as a salutary institutional expression of a presumption in favor of the legislature, and as a device to ensure that the striking down of legislation takes place only when its unconstitutionality is beyond question." (WALDRON, 2017, p. 13-14). 
BELLAMY, Richard. Political Constitutionalism: a republican defense of the constitutionality of democracy. United Kingdom: Cambridge University Press, 2007

BERNAL, Carlos. Unconstitutional constitutional amendments in the case study of Colombia: an analysis of the justification and meaning of the constitutional replacement doctrine. International Journal of Constitutional Law, v. 11, n. 2, 2013.

BRADBURY, John Charles; JOHNSON, Joseph. Do supermajority rules limit or enhance majority tyranny? Evidence from the US States, 1960-1997. Public Choice, 127, 2006.

BUCHANAN, James; TULLOCK, Gordon. The Calculus of Consent: logical foundations of constitutional democracy. Indianapolis: Liberty Fund, 1962.

CAMINKER, Evan. Thayerian deference to Congress and Supreme Court supermajority rules: lessons from the past. Indiana Law Journal, v. 78, 2003.

COLÓN-RÍOS, Joel. Weak constitutionalism: democratic legitimacy and the question of constituent power. Routledge, 2012.

CUSHMAN, Robert Eugene. Constitutional decisions by a bare majority of the court. Michigan Law Review, v. 19, n. 8, 1921.

DAWSON, Edward. Adjusting the presumption of constitutionality based on margin of statutory passage. Journal of Constitutional Law, v. 16, n. 1, 2013.

DIXON, Rosalind; STONE, Adrienne. Constitutional Amendment and Political Constitutionalism: a Philosophical and Comparative Reflection. Melbourne Legal Studies Research Paper, n. 703, 2014.

DWORKIN, Ronald. Response. Boston University Law Review, v. 90, n. 1059, 2010.

ELKINS, Zachary; GINSBURG, Tom; MELTON, James. The Endurance of National Constitutions. Cambridge University Press, 2009.

GARDBAUM, Stephen. Reassessing the new Commonwealth model of constitutionalism. International Journal of Constitutional Law, v. 8, n. 2, 2010. 
GEE, Graham; WEBBER, Grégoire. What is a political constitution? Oxford Journal of Legal Studies, v. 30, n. 2, 2010.

GOLDONI, Marco. Two internal critiques of political constitutionalism. International Journal of Constitutional Law, v. 10, n. 4, 2012.

HAMILTON, Alexander; MADISON, James; JAY, John. O Federalista. Brasília: Editora Universidade de Brasília, 1984.

HEINBERG, John Gilbert. Theories of majority rule. The American Political Science Review, 452, 1932.

KALYVAS, Andreas. Popular Sovereignty, Democracy, and the Constituent Power. Constellations, v. 12, n. 2, 2005.

KORNHAUSER, Lewis. Modelando cortes colegiadas. In: BOLONHA, Carlos; BONIZZATO, Luigi; MAIA, Fabiana (Orgs.). Teoria institucional e constitucionalismo contemporâneo. Curitiba: Juruá, 2016.

KRAMER, Larry D. The people themselves: popular constitutionalism and judicial review. Oxford University Press, 2004.

LANDAU, David. Abusive constitutionalism. University of California Davis Law Review, v. 47, 2013.

LIPKIN, Robert Justin. Which Constitution? Who decides? The problem of judicial supremacy and the interbranch solution. Cardozo Law Review, v. 23, n. 3, 2006.

LUTZ, Donald. Toward a Theory of Constitutional Amendment. The American Political Science Review, v. 88, n. 2, 1994.

MAY, Kenneth. A set of independent necessary and sufficient conditions for simple majority decision. Econometrica, v. 20, n. 4, 1952.

MENDES, Conrado Hübner. Constitutional Courts and Deliberative Democracy. United Kingdom: Oxford University Press, 2013.

NOVAK, Stéphanie. Majority Rule. Philosophy Compass, v. 9, n. 10, 2014.

RIGGS, Robert. When every vote counts: 5-4 decisions in the United States Supreme Court, 1900-90. Hofstra Law Review, v. 21, n. 3, 1993. 
ROZNAI, Yaniv. Unconstitutional Constitutional Amendments: the limits of amendment powers. Oxford University Press, 2017.

OFFE, Claus. Political legitimation through majority rule? Social Research, v. 50, n. 4, 1983.

SCHWARTZBERG, Melissa. Counting the many: the origins and limits of supermajority rule. Cambridge University Press, 2014.

SHUGERMAN, Jed Handelsman. A six-three rule: reviving consensus and deference on the Supreme Court. Georgia Law Review, v. 37, 2003.

TOCQUEVILLE, Alexis de. Democracy in America. New York: Barnes \& Noble, 2003.

TUSHNET, Mark. Taking the Constitution away from the Courts. New Jersey: Princeton University Press, 1999.

TUSHNET, Mark. How different is writing small from writing large. The Good Society, v. 18, n. 1, 2009.

WALDRON, Jeremy. Law and Disagreement. Oxford University Press, 1999.

WALDRON, Jeremy. The Core of the Case Against Judicial Review. The Yale Law Journal, v. 115, n. 1346, 2006.

WALDRON, Jeremy. A majority in the lifeboat. Boston University Law Review, v. 90, n. 1043, 2010.

WALDRON, Jeremy. Five to four: why do bare majorities rule on courts? The Yale Law Journal, v. 123, n. 1692, 2014.

WALDRON, Jeremy. Judicial review and political legitimacy. Texto da palestra proferida na Corte Constitucional da Colômbia, em 4/8/17.

ZELLMER, Sandra; MILLER, Kathleen. The fallacy of judicial supermajority clauses in state constitutions. U. Tol. L. Rev., v. 72, 2015. 